\title{
The use of prestressed fiberglass to reinforce concrete bending elements
}

\author{
Denis Panfilov, ${ }^{1, *}$, Alexander Pischulev ${ }^{1}$, and Yuriy Zhiltsov ${ }^{1}$ \\ ${ }^{1}$ Samara State Technical University, Institute of Architecture and Civil Engineering, \\ 194Molodogvardeyskaya St., 443001, Samara, Russia
}

\begin{abstract}
The article presents the research results of mathematical models of bending concrete elements reinforced with prestressed fiberglass reinforcement. The investigations are built on the basic positions of the nonlinear deformation model, taking into account the nonlinear work of concrete. The samples were calculated with consideration for the deformation diagrams of materials obtained experimentally using the Lira CAD 2014 software package. The article also covers the current practice of using fiberglass to reinforce concrete bearing structures without prestressing, as well as the current normative documents regulating the use of fiberglass reinforcement in the Russian Federation, regulatory and state standards containing information on the strength and deformation properties of fiberglass reinforcement, and the results of physical tests of fiberglass reinforcement for tension. Based on the results of the study, we performed the analysis of fiberglass reinforcement use with and without prestressing. The studies presented in the article show that the use of prestressed fiberglass reinforcement makes it possible to increase the rigidity and fracture toughness of bending concrete elements.
\end{abstract}

\section{Introduction}

The use of fiberglass as a reinforcing element of concrete structures is hampered by the following factors:

- low adhesion of fiberglass reinforcement with concrete;

- low deformation modulus of fiberglass reinforcement.

The first drawback can be eliminated by using special anchoring devices to ensure the concurrent work of concrete and fiberglass reinforcement. The second disadvantage can be eliminated by changing the mechanical properties of fiberglass fibers, which will lead to the creation of a new material and the rejection of existing samples of fiberglass reinforcement manufactured in accordance with State Standard 31938-2012 [2], or by creating a prestressed state.

\footnotetext{
*Corresponding author: panda-w800i@yandex.ru
} 


\section{Materials and methods}

The purpose of this work was to study the strength and deformation properties of fiberglass reinforcement, manufactured at a specialized plant SVSK Production company in Togliatti (Russia) in accordance with Specification No. 5769-001-21121765-2013 [1] and State Standard 31938-2012 [2]; the work also carries out experimental studies of fiberglass reinforcement samples, in continuation of the studies undertaken [3-9], to assess the feasibility of using such reinforcement as prestressed one in bending concrete elements. The prestress allows creating a reverse sign force in the unloaded structure that will increase the rigidity and fracture toughness of reinforced concrete elements.

\section{Results}

To obtain experimental data on the actual relationship between stresses and deformations, we carried out tests of fiberglass reinforcement for tension. For this reason, we made samples of fiberglass reinforcements with diameters of 4, 6, 8, 10, $12 \mathrm{~mm}$. The length of the samples was assumed to be $1.2 \mathrm{~m}$. The prototype designs are shown in Figure 1 and include pieces of fiberglass reinforcement, which are equipped with gripping devices at their ends. The construction of the gripping devices is a steel tube with a length of $350 \mathrm{~mm}(35$ diameters of the test rod) and a diameter of $20 \mathrm{~mm}$. The prototype of the rod is pasted into the gripping device using epoxy resin. The adopted design of the gripping device makes it possible to fix the test specimen in the tensile machine securely and transfer the breaking force to the sample, not allowing its local damage in the press clamps. The general view of samples of fiberglass reinforcement is shown in Figure 1.

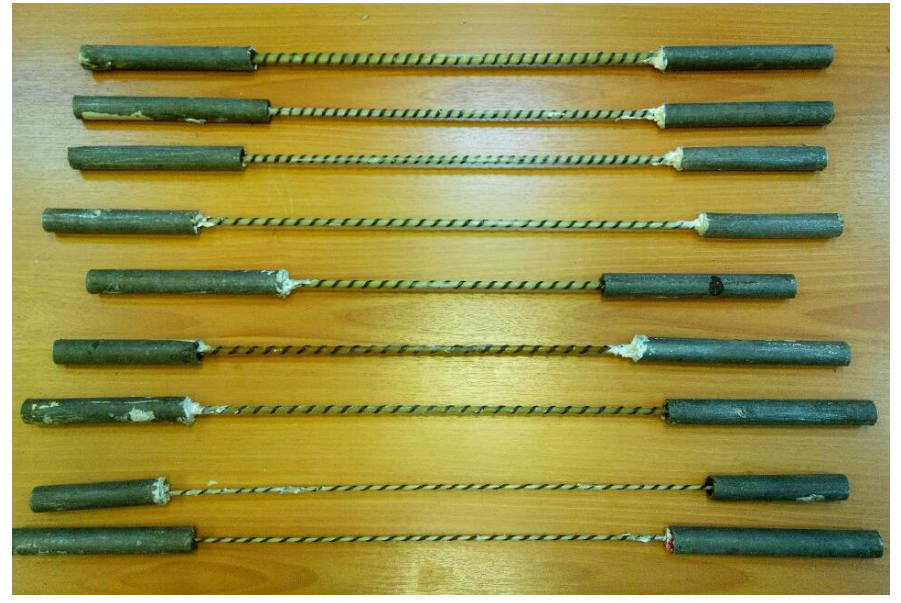

Fig. 1. Samples of fiberglass reinforcement.

To measure the controlled parameters, we developed a clamp design to fix the hour-type indicators on the sample during the research, with a measurement accuracy of $0.01 \mathrm{~mm}$. The general view of the test set for the investigation of fiberglass reinforcement is shown in Figure 2. 


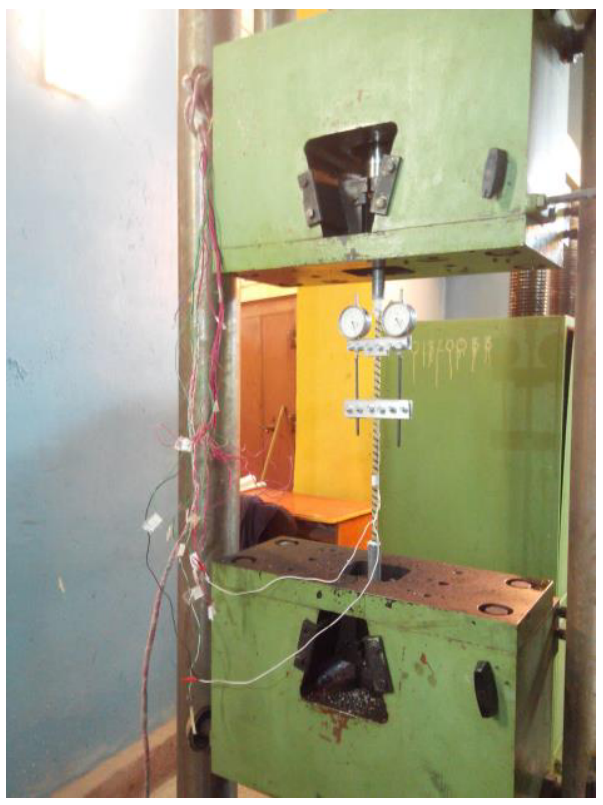

Fig. 2. General view of a test set for the research of fiberglass reinforcement.

To measure the relative deformations of the order of $1 * 10^{-6}$ Units of Relative Deformations, tensometric sensors were attached to the test sample. The tensometric station IDZ-1 was used as the recording equipment. During the tests, the error due to temperature deformation was eliminated by using tensometric compensation.



$z_{Y}$

Fig. 3. The diagram of normal stresses distribution of the finite element model.

Tests were carried out on the basis of the research and industrial laboratory of the Building Structures Department of Samara State Technical University, Institute of Architecture and Civil Engineering on a tensile machine R-50. The load was set in steps of $1 \mathrm{kN}$

According to the testing results of the reinforcement for the break, it was established:

1. The relationship between stresses and deformations is practically linear, which characterizes the work of fiberglass reinforcement as a conditionally elastic material.

2. The elasticity modulus along the fibers is about 55,000 $\mathrm{MPa}$ and remains conditionally constant at all loading stages. 
3. Destruction of the sample with a diameter of $10 \mathrm{~mm}$ occurred at a load of $39 \mathrm{kN}$. The character of the sample destruction is brittle, as a result of a consistent instantaneous breakage of fiberglass reinforcement fibers.

4. Temporary resistance to tearing of fiberglass reinforcement was $39 \mathrm{kN}$.

As prototypes, it is proposed to manufacture single-span hinged-supported beams loaded with a uniformly distributed load along the length. The beam structures are shown in Figure 4.

The sample is made of concrete B25 with the following geometric characteristics: height $-120 \mathrm{~mm}$, width $-120 \mathrm{~mm}$, length $-1000 \mathrm{~mm}$.

The analysis of the tension-deformation state of a bending concrete element reinforced with prestressed fiberglass reinforcement was performed with the help of a spatial finite element model created in the Lira-CAD 2014 software package with stepwise loading of the structure and taking into account the nonlinear deformation of concrete.

The design of the sample included a rod of prestressed fiberglass reinforcement installed in the stretched zone of the element as well as a spatial metal frame consisting of longitudinal working reinforcement and transverse reinforcement installed in the bearing zones of the beam. Longitudinal reinforcement installed along the upper edge of the beam at the stage of prestressing the sample (the tension of the reinforcement to the concrete) takes the tensile forces from the moment of the opposite sign. As the sample is loaded with an external load, the longitudinal steel reinforcement begins to perceive compressive forces, i.e. it is in the compressed zone of concrete. Transverse reinforcement provides the strength of oblique sections in the bearing zones of the beam. When manufacturing a sample in a stretched zone a channel is provided for installing prestressed fiberglass reinforcement. The tension of the reinforcement is carried out on concrete, after it takes up $70 \%$ of strength. After the rod is tensioned, it is inserted into the previously prepared channel, and the space between the gripping devices of the rod (tubes) and the thrust plate of the beam is selected by calibrated metal washers.

The samples were tested on a universal test machine GRM-1. The general view of the test machine and the nature of the destruction of the experimental sample are shown in Figures 4 and 5. The graphs of dependence of the deflection and width of the structure crack opening from the load are shown in Fig. 6 and 7.

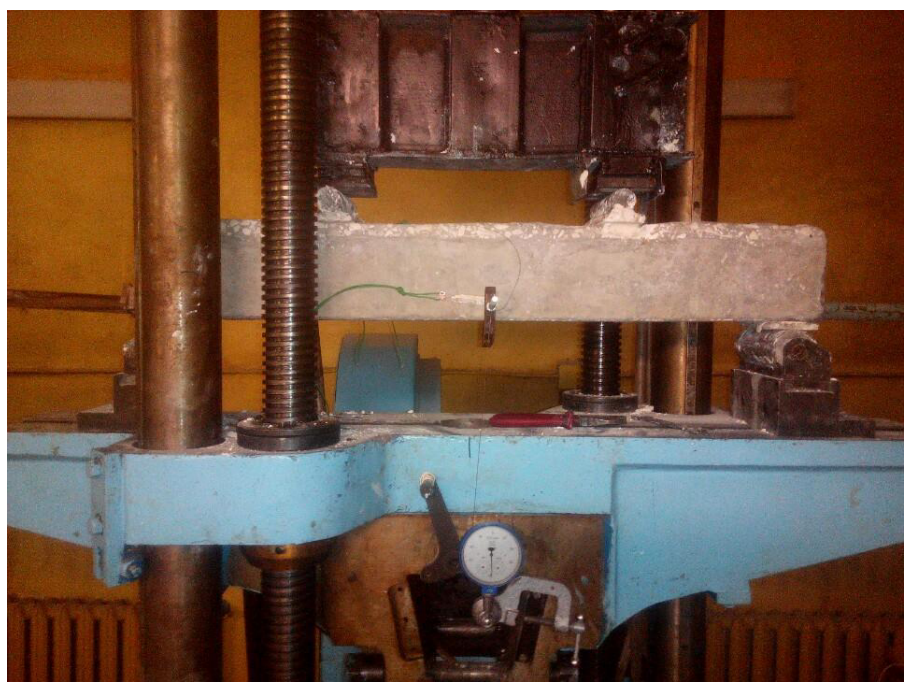

Fig. 4. General view of the test machine with a sample. 


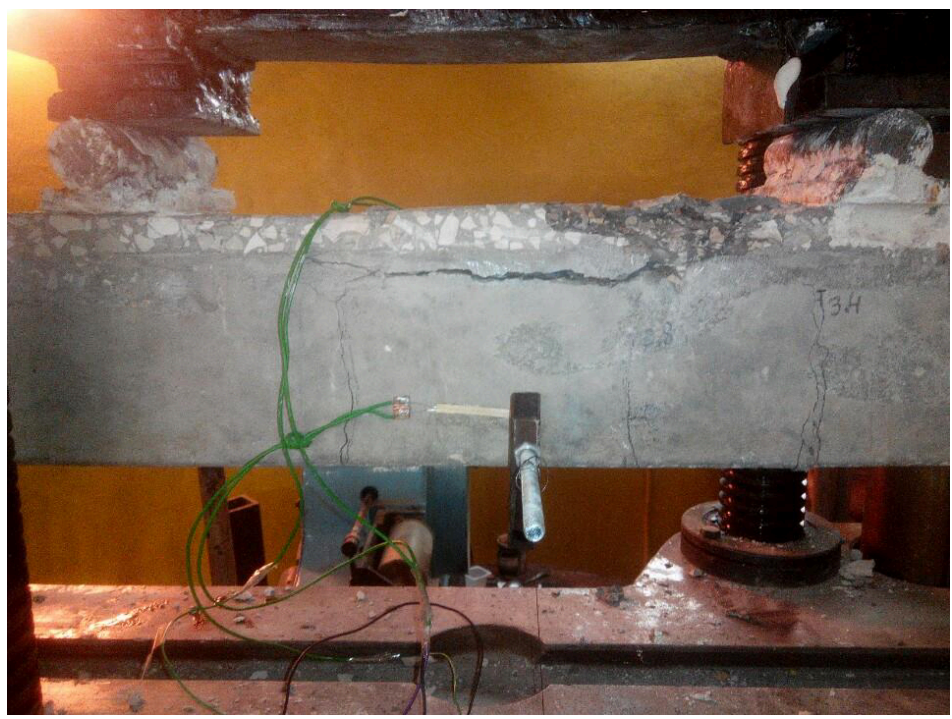

Fig. 5. Brittle destruction of the sample at a load of $660 \mathrm{kN}$.



Fig. 6. Graph of dependence of the structure deflection on the load.

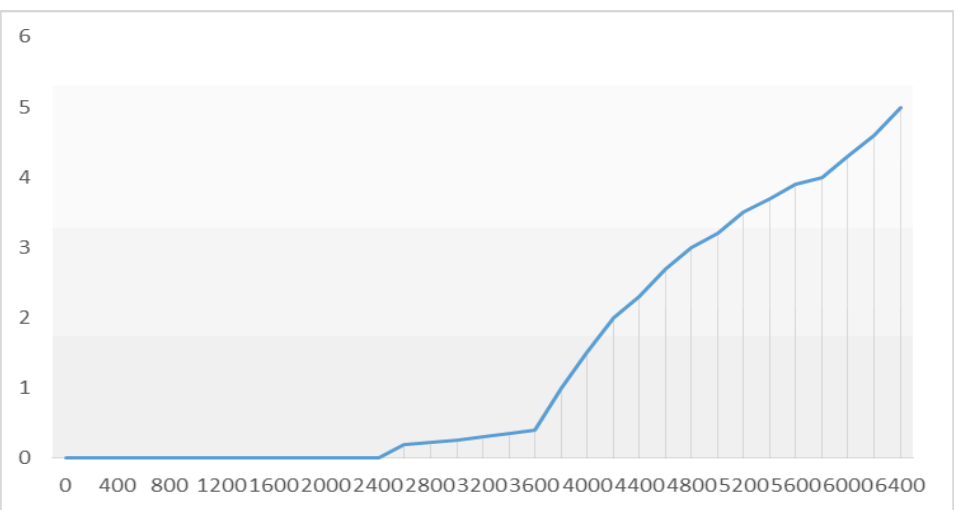

Fig. 7. Graph of the dependence of the structure crack width on the load. 


\section{Conclusion}

Based on the results of research and comparison of calculated and experimental data, we can draw the following conclusions:

1. Fiberglass reinforcement has higher strength characteristics, but has a lower deformation modulus compared to steel. A low elasticity modulus limits the use of fiberglass reinforcement as a reinforcing element of concrete. To reduce the negative effect of a low elasticity modulus in work, it is suggested to use prestressed reinforcement.

2. Based on the results of non-linear calculations in Lira-CAD 2014 software and fullscale experiments, it is proved that the use of pre-stress fiberglass reinforcement makes it possible to increase the rigidity and fracture toughness of bending elements.

3. Based on the results of experimental studies of bending concrete beams with prestressed fiberglass reinforcement, the following was established: after reaching the limiting value of the cracking formation moment and the formation of the first crack, due to the loss of adhesion of the prestressed reinforcement to the concrete of the stretched zone, following the increased load, there is a sharp increase in deflections and width of crack opening, and the nature of the destruction of the sample is brittle, with the delamination of the compressed concrete zone.

\section{References}

1. Specification № 5769-001-21121765-2013 Fiberglass Plastic Reinforcement (Composite) (2013)

2. The State Standard 31938-2012 Composite Polymer Reinforcement for the Reinforcement of Concrete Structures. General Specifications. 34 (2013)

3. D.A. Panfilov, Yu.V. Zhiltsov, K.I. Gimadetdinov, Traditions and Innovations in Construction and Architecture. Construction, 111-115 (2015)

4. A.A. Budko, A.A. Potekhin, A.A. Akopyan, Technical Sciences: Tendencies, Prospects and Technologies of Development. Collection of scientific works on the results of the international scientific and practical conference, 148-152 (2016)

5. T.A. Mukhamediev, D.V. Kuzevanov, Construction Mechanics and Calculation of Structures 4, 18-22 (2016)

6. A.R. Wolik, A.A. Pochebyt, Modelling and Mechanics of Structures 4, 18 (2016)

7. Valery B. Filatov, Alexander A. Suvorov, Procedia Engineering 153, 144-150 (2016)

8. S.S. Mordovsky, Urban Construction and Architecture 3, 26-28 (2013)

9. M.A. Ivlev, I.V. Nedoseko, Urban Construction and Architecture 4, 86-91 (2012) 